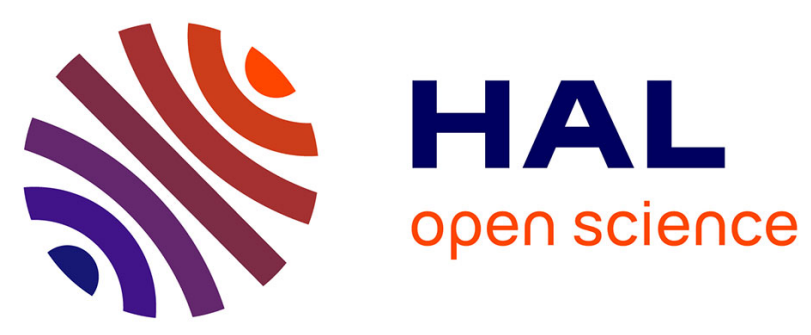

\title{
Intelligence is negatively associated with the number of functional somatic symptoms
}

Eva M Kingma, Lineke M Tak, Martijn Huisman, Judith G M Rosmalen

\section{To cite this version:}

Eva M Kingma, Lineke M Tak, Martijn Huisman, Judith G M Rosmalen. Intelligence is negatively associated with the number of functional somatic symptoms. Journal of Epidemiology and Community Health, 2009, 63 (11), pp.900-n/a. 10.1136/jech.2008.081638 . hal-00477881

\section{HAL Id: hal-00477881 \\ https://hal.science/hal-00477881}

Submitted on 30 Apr 2010

HAL is a multi-disciplinary open access archive for the deposit and dissemination of scientific research documents, whether they are published or not. The documents may come from teaching and research institutions in France or abroad, or from public or private research centers.
L'archive ouverte pluridisciplinaire HAL, est destinée au dépôt et à la diffusion de documents scientifiques de niveau recherche, publiés ou non, émanant des établissements d'enseignement et de recherche français ou étrangers, des laboratoires publics ou privés. 


\section{TITLE}

Intelligence is negatively associated with the number of functional somatic symptoms

\section{Corresponding author and contact information:}

Judith G.M. Rosmalen, PhD

Interdisciplinary Center for Psychiatric Epidemiology, University Medical Center Groningen

P.O. Box 30.001, 9700 RB, Groningen, The Netherlands

Tel: $+31-50-3612079 \quad$ Fax: $+31-50-3619722 \quad$ E-mail:

J.G.M.Rosmalen@ med.umcg.nl

\section{Authors:}

Eva M. Kingma, BSc

Lineke M. Tak, MD

Martijn Huisman, PhD

Judith G.M. Rosmalen, PhD

\section{Affiliation of all authors:}

Interdisciplinary Center for Psychiatric Epidemiology, University Medical Center Groningen, University of Groningen, The Netherlands

Keywords: functional somatic symptoms, intelligence, somatization, general population, longitudinal 


\section{ABSTRACT}

Background: Functional somatic symptoms (FSS), symptoms that cannot be conclusively explained by organic pathology, have a poorly understood aetiology. Our aim is to study intelligence as a risk factor for FSS. We hypothesize that intelligence is negatively associated with the number of FSS. To investigate the specific role of intelligence in FSS as opposed to medically explained symptoms (MES), we compared associations of intelligence with FSS with those of intelligence with MES. We hypothesize that lifestyle factors and socioeconomic factors mediate the relation between intelligence and both FSS and MES, whereas psychological distress is especially important for FSS.

Methods: We performed all analyses in a longitudinal study with two measurement waves in a general population cohort of 947 participants (age 33-79 years, $47.9 \%$ male). We used the Generalized Aptitude-Test Battery to derive an index for general intelligence, and the somatization section of the Composite International Diagnostic Interview to measure the number FSS and MES.

Results: General intelligence was significantly associated with the number of FSS. The association of intelligence and FSS but not MES was mediated by work-situation: participants of lower intelligence that report more FSS are more often (unwanted) economically inactive. No evidence was found for a mediating role of psychological distress in the association of intelligence with FSS, even though distress was an important predictor of FSS.

Conclusion: Intelligence is negatively associated with the number of FSS in the general population. Part of the association of intelligence with FSS is explained by a more unfavourable work situation of adults of lower intelligence. 


\section{INTRODUCTION}

Functional somatic symptoms (FSS) are somatic symptoms that cannot be conclusively explained in terms of conventionally defined organic pathology. ${ }^{1 ; 2}$ FSS constitute a major health care problem because they are common, disabling for patients and costly for society. ${ }^{3-5}$ Doctors often have difficulties in dealing with patients who present FSS. They want to reassure their patient, but at the same time fail to provide an acceptable explanation for the occurrence of FSS. Most doctors explain FSS as a result of psychological distress. ${ }^{6 ; 7}$ Patients are often dissatisfied with those psychological labels for their somatic symptoms ${ }^{8}$ and prefer a somatic diagnosis. ${ }^{9}$ This incorrect dualistic view of both patients and doctors on the nature of symptoms is a major obstacle to an effective treatment relation.

Although the aetiology of FSS is poorly understood, it is becoming increasingly clear that underlying processes are multifactorial. Recent research and theory in this area suggest complex interactions between biological, psychological and social factors in the development and perpetuation of FSS. ${ }^{10-12}$ Intelligence is an interesting vulnerability factor to study in the context of FSS, because it is associated with several risk factors for development and perpetuation of FSS. Although intelligence itself has never been studied as a risk factor for FSS, studies towards related constructs such as lower education level suggest an association

with the occurrence of somatic symptoms in general practice. ${ }^{13-19}$ In contrast to FSS, various studies have looked at the relation between intelligence and various kinds of medically explained somatic health problems. These studies have consistently found a negative association between intelligence and somatic morbidity or mortality. ${ }^{20} 21 ; 22$ 
Two commonly studied non-exclusive mediating mechanisms in the relation between intelligence and health are socioeconomic factors and lifestyle factors. ${ }^{23}$ Intelligence is associated with more education, and thereafter with more professional occupations that might place the person in healthier environments. In addition, intelligence is associated with a healthier diet, more exercise, and less smoking and problem drinking. Both mechanisms seem to be involved in the relation between intelligence and somatic morbidity and mortality, however, it is unknown to which degree these mechanisms are involved in the development of FSS. A third potential mediator is psychological distress, since both intelligence and somatic symptoms are known to be associated with an increased prevalence of anxiety and depression. ${ }^{24-26}$ Given the fact that most doctors explain FSS as a result of psychological distress, ${ }^{6 ; 7}$ the question arises whether its mediating role might be more important in the relation of intelligence with FSS than in that with medically explained symptoms (MES).

This study aims to clarify the association between intelligence and FSS in a population-based cohort. We hypothesize that intelligence is negatively associated with the number of FSS. We hypothesize that socioeconomic factors, lifestyle factors and psychological distress mediate this relation. To investigate the specific role of intelligence in FSS as opposed to MES, we compared associations of intelligence with FSS with those of intelligence with MES. Whereas we expected more or less similar associations with both outcomes, we expected that distress would be a mediator of the association of intelligence with FSS but not with that of intelligence with MES. 


\section{METHODS}

\section{Population}

The current study has been performed in a cohort derived from PREVEND (Prevention of REnal and Vascular ENd stage Disease), a major population cohort study at the University Medical Center Groningen investigating microalbuminuria as a risk factor for renal and cardiovascular disease. The recruitment of participants for PREVEND has been described elsewhere. ${ }^{27}$ Basically, the PREVEND baseline population consists of 8592 subjects randomly selected from the population of the city of Groningen with oversampling for albuminuria. Selection of subjects for the purpose of the current study was aimed to recruit a sample representative of the general population of Groningen, while simultaneously rectifying PREVEND's oversampling for albuminuria. Research assistants handed over invitations to 2554 participants who visited the outpatient clinic of PREVEND. Measurements were completed by a total of 1094 participants (43\%), forming the population cohort. PREVEND participants who were invited for the current study but did not participate and PREVEND participants who agreed to participate did not significantly differ concerning gender, age and scores on a 12 -item neuroticism scale. ${ }^{28}$ Follow-up measurements, performed approximately two years later, were completed by a total of 976 participants. The study was approved by the medical ethics committee and was conducted in accordance with the guidelines of the declaration of Helsinki. Written informed consent was obtained from all participants.

\section{Assessment of intelligence}

At baseline, the intelligence of the participants was measured using the computerized version of the General Aptitude-Test Battery (GATB) version B 1002-B. ${ }^{29}$ The GATB consists of a combination of tests that measure nine aptitudes. The aptitude intelligence is measured by 
three tests: 1) a dimensional space test, 2) a vocabulary test, and 3) an arithmetic reasoning test. All participants performed the intelligence test in groups of at most nine persons. Before the start of each test, a test assistant provided test-instructions and provided computer help when necessary. Tests were not started before the test assistant was certain that all participants had successfully completed the practice sessions. To construct a general intelligence score, we summed standardized scores on each of the three subtests (a total of 1061 completed GATBs were available).

\section{Assessment of somatic symptoms}

Participants completed the somatization section of the Composite International Diagnostic Interview (CIDI). The CIDI is a fully structured diagnostic interview developed by the World Health Organization and has adequate test-retest reliability and validity. ${ }^{30}$ A fully computerized version of the CIDI 2.1, suitable for self- administration, was applied. Trained interviewers were present for questions and for people that needed computer help. In the CIDI somatization section, 43 FSS (listed in appendix 1) are assessed through asking "have you ever had" this symptom. Symptoms are considered present when they meet severity criteria, i.e. provoking a health care visit. If these criteria are met, the interview assesses in a hierarchical fashion whether a medical doctor diagnosed a symptom as due to physical illness or injury, or whether a symptom was caused by the use of medication, drugs or alcohol. If the participant reported that a medical doctor diagnosed the symptom as due to physical illness or injury, the symptom was scored as a MES. If all inquiries were negative for medical explanations, the symptom was scored as a FSS. Sexual indifference was excluded from the analyses since it is not surveyed in the CIDI whether this symptom provoked a health care visit. Participants first completed the CIDI lifetime version measuring lifetime FSS and lifetime MES (a total of 1088 completed CIDIs were available). Approximately two years 
later, participants were re-interviewed and completed the CIDI 12-months version, in which the occurrence of the 43 symptoms in the previous year is surveyed (964 completed CIDIs were available). Since we expect that the 12-months recall of symptoms is less likely to be affected by cognitive abilities than lifetime recall, we constructed sum scores of 12-months FSS and 12-months MES for our main analyses. Additionally, sum scores of new-onset FSS and MES were constructed by comparing the MES and FSS reported in the CIDI 12-months interview with those reported in the CIDI lifetime interview.

\section{Assessment of lifestyle factors}

Body mass index (BMI) was calculated as the ratio between weight and the square of height $\left(\mathrm{kg} / \mathrm{m}^{2}\right)$ measured at baseline. Smoking, alcohol consumption, and exercise frequency were assessed by written self-report at baseline. Smoking was categorized in non-smoker, 1-5, 6$10,11-15,16-20$ or more than 20 cigarettes/day. Alcohol consumption was categorized in never or almost never, 1-4 units/month, 2-7 units/ week, 1-3 units/day and $\geq 4$ units/day). Exercise frequency was categorized as never, once/week, twice or more/week.

\section{Assessment of socio-economic factors}

Information on income, educational level, and work situation was retrieved from questionnaires that were filled in at the time of inclusion into PREVEND. Income was measured through the gross monthly household income $(<1200,1200-1799,1800-2199$, $2200-2799,2800-3799,3800-5800$, or $>5800$ guilders) divided by the square root of the

number of people living in the household. ${ }^{31}$ The variable education was made up of the following categories: not applicable, low, middle, or high educational level. Low educational level was defined as lower secondary education or less, middle education was defined as higher secondary education, and high education was defined as tertiary education. Working 
situation was categorized in the following categories: employed (i.e. currently having a job), willingly unemployed (i.e. housekeeping or retired), or unwillingly unemployed (i.e. job seeker or unable to work).

\section{Assessment of psychological distress}

Psychological distress was measured using the Dutch translation of the 12-item General Health Questionnaire (GHQ-12) measuring current psychological distress. ${ }^{32}$ This questionnaire was completed at home before the visit to the research facilities at baseline. The GHQ-12 comprises 12 questions dealing with two major classes of phenomena: inability to continue to carry out one's normal healthy functions and the appearance of new phenomena of a distressing nature (e.g., being able to enjoy day-to-day activities, losing sleep over worry, thinking of yourself as worthless). The respondent is asked whether he or she has recently experienced a particular symptom or item of behavior on a scale ranging from "less than usual" to "much more than usual". No items pertaining to somatic symptoms are included in the GHQ-12. The GHQ-12 exceeded the criterion for acceptable instrument internal consistency reliability of 0.70 or greater. ${ }^{33} \mathrm{We}$ calculated a GHQ sum score using the traditional GHQ scoring method of $0-0-1-1 .{ }^{34}$ Missing data were imputed according to the method of corrected item mean substitution, if at least half of the items were completed. ${ }^{35}$

\section{Statistical analyses}

We used SPSS 16.0 (SPSS Inc, Chicago, IL, USA) to perform our statistical analyses. Variables that were not normally distributed (sum scores of FSS and MES) were log transformed. The association between the log-transformed sum scores of FSS and MES was tested using Pearson's correlation coefficient. We performed univariable linear regression analyses to test whether subject characteristics (age, sex, body mass index, smoking, alcohol 
consumption, exercise frequency, income, educational level, work situation, and psychological distress) were associated with general intelligence, 12-months FSS, or with 12months MES. We performed multivariable linear regression analyses to test whether general intelligence was associated with the number of 12-months FSS or 12-months MES. We performed multivariable linear regression analyses to test whether general intelligence was associated with the number of 12-months FSS or 12-months MES. In addition, we repeated these analyses using, instead of general intelligence, scores on the dimensional space subtest, vocabulary subtest and arithmetic reasoning subtest as separate predictors. Next, we performed multivariable regression analyses, including potential mediators of the associations with FSS and MES. Factors were only included if they proved to be associated with both intelligence and the outcome. Since FSS and MES are correlated, we repeated all analyses adjusting FSS for MES and vice versa. Additionally, we tested whether intelligence predicted new-onset FSS and MES applying the same steps. All multivariable analyses were adjusted for the potential confounders gender $(0=\mathrm{M}$ and $1=\mathrm{F})$ and age (in years to one decimal place), since these variables are both associated with intelligence ${ }^{36}$ 37-39 and FSS. ${ }^{39-42}$. 


\section{RESULTS}

\section{Demographic characteristics}

The current study cohort consisted of 947 participants for which intelligence sores and symptom scores were available (47.9\% males), with a mean age of 52.7 (SD 11.2 years, minimum 33 years, maximum 79 years). Of the participants, $25.5 \%$ had a certificate of lower education; $27.0 \%$ a certificate of middle education and $43.1 \%$ a certificate of higher education. Test scores of general intelligence were normally distributed (skewness $=-0.099$, kurtosis $=-0.476)$. The correlation between the sum scores of FSS and MES was 0.172 $(\mathrm{p}<0.001)$.

\section{Associations between subject characteristics and intelligence}

Table 1 summarizes the univariable associations between subject characteristics and intelligence. Intelligence was significantly associated with lower age and being male. Considering lifestyle factors, higher intelligence was associated with having a lower BMI, less smoking, more alcohol consumption, and exercising. Higher intelligence was also associated with a higher educational level, a more favourable work situation and a higher income. However, intelligence was not associated with psychological distress $(\beta=-0.019, \mathrm{t}=-$ $0.591, \mathrm{p}=0.554)$. This means that psychological distress could not be a mediator of the association of intelligence with both outcomes, and this factor was therefore not examined in multivariable analyses.

\section{Associations between subject characteristics and somatic symptoms}

Table 2 summarizes the univariable associations between subject characteristics and the number of 12-months FSS or 12-months MES. Older age was related to having more MES 
but not FSS; females had more MES and FSS than males. Both FSS and MES were associated with a higher BMI, not consuming alcohol and a low exercise frequency. Smoking was associated with FSS but not with MES. All socio-economic factors were negatively associated with both FSS and MES, indicating that participants with a lower income, a lower educational level and less favourable work situation more often reported somatic symptoms.

Psychological distress was positively associated with both FSS and MES, but the effect size for FSS is about twice the size of the effect size for MES. When repeating these analyses using new-onset FSS and MES as an outcome, the results remained essentially the same.

\section{Associations between intelligence and somatic symptoms}

Table 3 summarizes the multivariable associations between intelligence and the number of 12-months FSS or MES. Linear regression analyses indicated that general intelligence was negatively associated with the number of FSS $(\beta=-0.084, t=-2.299, p=0.022)$ and MES $(\beta=-$ 0.095, $\mathrm{t}=-2.652, \mathrm{p}=0.008)$. When studying the subtests that composed general intelligence, we found that the association was explained by the vocabulary subtest and the arithmetic reasoning subtest, but not by the dimensional space subtest. Introduction of the potential mediators into the model removed the association of intelligence with somatic symptoms, but evidence for mediation was limited to work-situation in the relation of intelligence with FSS. 


\section{DISCUSSION}

This study demonstrated that intelligence was negatively associated with the number of reported FSS and MES. The association of intelligence with FSS was mediated by the worksituation of participants, suggesting that adult men and women of lower intelligence that report more functional somatic symptoms are more often (unwanted) economically inactive. In contrast to our expectations, no evidence was found for a mediating role of psychological distress in the association of intelligence with FSS, even though distress was an important predictor of FSS.

There are several strengths of this study. First, we collected detailed information on a large number of FSS and performed our analyses on a continuous variable for the number of FSS. In many studies concerning FSS, arbitrary cut-off scores are used despite the lack of consensus about where to put the cut-off and the loss of information as a result of artificial dichotomizing of variables. ${ }^{40 ; 43}$ Second, we measured both FSS and MES using the same instrument, enabling comparisons between these types of symptoms and their associations with intelligence. Third, generalizability of our results is good, because we used a large population cohort without applying strict inclusion criteria.

When interpreting our study results, the following limitations should be taken into account. First, we measured intelligence in adult participants. Although general intelligence is regarded as a trait that is stable from infancy into middle age, ${ }^{44}$ it can not be excluded that reverse causality, in which somatic symptoms contribute to lower intelligence scores, is playing a role. We performed additional analyses (results not shown) including only new-onset symptoms (i.e. onset after measurement of intelligence) as outcomes, which provided 
essentially the same results as the analyses that are reported here, indicating that the effect of reverse causality may have been negligible. However, this does not exclude the possibility that pre-existing morbidity causes both low intelligence scores and new somatic symptoms. Second, recall bias may have attenuated the reliability of the CIDI to measure FSS and $\mathrm{MES},{ }^{45}$ and recall bias is likely to be associated with intelligence because people with lower intelligence have lower memory capacity. ${ }^{46}$ We limited our analyses to symptoms that occurred in the last 12 months, which will have reduced the effect of recall bias. Moreover, it should be noted that the expected effect of recall bias on our results would be to reduce associations of intelligence with reported symptoms, indicating that our results are more likely to be underestimations rather than overestimates. Finally, the fact that we measured symptoms via self-report may be regarded as a limitation. However, symptoms were only defined as being functional if it was reported that a medical doctor had indicated that all inquiries were negative for medical explanations. Moreover, the finding that psychological distress as measured by GHQ-scores was much more strongly associated with FSS than with MES underlines the etiological difference between those symptoms.

Our study demonstrates that intelligence is negatively associated with the number of FSS and MES. We are the first to study the direct relation between FSS and intelligence, but a negative association between intelligence and morbidity or mortality has been a consistent finding. ${ }^{20-22}$ Focusing on the association of intelligence with covariates, most of our results seemed to be in line with findings from previous studies. Socioeconomic factors and most lifestyle factors were negatively associated with intelligence. Only for alcohol consumption did we observe a positive association (i.e. more alcohol consumption in those with higher intelligence). Some studies have found the same result ${ }^{47 ; 48}$ whereas other studies found the opposite. ${ }^{49}$ It should be realized that we used a continuous measure of alcohol consumption, 
mainly indicating social drinking (which might be related to higher socioeconomic status ${ }^{50}$ ) with only a minority being problem drinkers. Another unexpected finding might be that psychological distress was not related to intelligence. Our initial hypothesis that one of the major differences between the associations of intelligence with FSS and MES would be that the association with FSS was mediated by distress therefore was not confirmed. Previous studies towards intelligence and GHQ-scores have been contrasting, with either a negative association between childhood intelligence and the GHQ-28 in middle-aged women ${ }^{48}$ or no association between current intelligence and GHQ-30 scores in middle-aged participants from the Whitehall II study. ${ }^{22}$

The associations of socioeconomic and lifestyle factors with somatic symptoms were in the expected directions, with the exception of smoking in relation to MES. Despite its wellknown association with morbidity and mortality, ${ }^{51}$ we observed no association of smoking with MES. This lack of association might be due to the fact that we measure somatic complaints and not diagnoses, and most complaints included in the CIDI are not associated with smoking-related diseases such as cardiovascular and pulmonary disease.

Our multivariable models show that the association of intelligence with FSS and MES is removed after adding lifestyle and socioeconomic factors into the model. However, there was only clear evidence for mediation of the association with FSS by work-situation. The interpretation of these findings is not obvious, but one possibility is that participants without a job do not have a day-to-day distraction from their physical complaints. Furthermore, unemployment and especially unwanted employment is clearly linked to devastating individual effects, such as financial hardship. ${ }^{52}$ It could be hypothesized that the resulting psychological distress is responsible for the association between work situation and FSS. 
Although we did indeed find an association between psychological distress and FSS, this association was not responsible for the relation between work-situation and FSS.

Finally, our results indicate that verbal components of intelligence are more important than performance components of intelligence in predicting somatic complaints. One explanation for this finding could be that linguistic skills might be of more use when it comes to communicating with doctors and when seeking social support when suffering from somatic complaints or psychosocial stress. Psychosocial stress has been assumed to play a role in development and perpetuation of $\mathrm{FSS}^{4 ; 12 ; 53}$ and MES. ${ }^{54}$

In conclusion, lower general intelligence was associated with a higher number of FSS and MES in the general population. Part of the association of intelligence with FSS was explained by a more unfavourable work situation of adults of lower intelligence. 


\section{FUNDING}

Funding for this study was provided by the Netherlands Organization for Scientific Research (Pionier 900-00-002). This organization had no further role in study design; in the collection and interpretation of data; in the writing of the report; and in the decision to submit the paper for publication. 


\section{BOX: "What this paper adds"}

\section{Paragraph 1: What is already known on this subject?}

Recent research and theory in this area suggest complex interactions between biological, psychological and social factors in the development and perpetuation of Functional Somatic Symptoms (FSS). Intelligence is an interesting vulnerability factor to study in the context of FSS, because it is associated with several risk factors for development and perpetuation of FSS.

\section{Paragraph 2: What does this study add?}

Our results reveal a significant negative association between intelligence and the number of FSS in a general population-cohort. Part of the association of intelligence with FSS is explained by a more unfavourable work situation of adults of lower intelligence. No evidence was found for a mediating role of psychological distress in the association of intelligence with FSS, even though distress was an important predictor of FSS. 


\section{REFERENCES}

(1) Fink P, Rosendal M, Olesen F. Classification of somatization and functional somatic symptoms in primary care. Australian and New Zealand Journal of Psychiatry 2005; 39(9):772-781.

(2) Stone J, Wojcik W, Durrance D, Carson A, Lewis S, MacKenzie L et al. What should we say to patients with symptoms unexplained by disease? The "number needed to offend". British Medical Journal 2002; 325(7378):1449-1450.

(3) Nimnuan C, Hotopf M, Wessely S. Medically unexplained symptoms - An epidemiological study in seven specialities. Journal of Psychosomatic Research 2001; 51(1):361-367.

(4) Katon WJ, Walker EA. Medically unexplained symptoms in primary care. Journal of Clinical Psychiatry 1998; 59:15-21.

(5) Barsky AJ, Orav EJ, Bates DW. Somatization increases medical utilization and costs independent of psychiatric and medical comorbidity. Archives of General Psychiatry 2005; 62(8):903-910.

(6) Woivalin T, Krantz G, Mantyranta T, Ringsberg KC. Medically unexplained symptoms: perceptions of physicians in primary health care. Family Practice 2004; 21(2):199-203.

(7) Wileman L, May C, Chew-Graham CA. Medically unexplained symptoms and the problem of power in the primary care consultation: a qualitative study. Family Practice $2002 ; 19(2): 178-182$. 
(8) Rief W, Isaac M. Are somatoform disorders 'mental disorders'? A contribution to the current debate. Current Opinion in Psychiatry 2007; 20(2):143-146.

(9) Bakal D, Steiert M, Coll P, Schaefer J. An experiential mind-body approach to the management of medically unexplained symptoms. Medical Hypotheses 2006; 67(6):1443-1447.

(10) Brown RJ. Psychological mechanisms of medically unexplained symptoms: An integrative conceptual model. Psychological Bulletin 2004; 130(5):793-812.

(11) Rief W, Broadbent E. Explaining medically unexplained symptoms-models and mechanisms. Clinical Psychology Review 2007; 27(7):821-841.

(12) Deary V, Chalder T, Sharpe M. The cognitive behavioural model of medically unexplained symptoms: A theoretical and empirical review. Clinical Psychology Review 2007; 27(7):781-797.

(13) van der Windt DAWM, Dunn KM, Spies-Dorgelo MN, Mallen CD, Blankenstein AH, Stalman WAB. Impact of physical symptoms on perceived health in the community. Journal of Psychosomatic Research 2008; 64(3):265-274.

(14) Hiller W, Rief W, Brahler E. Somatization in the population: from mild bodily misperceptions to disabling symptoms. Social Psychiatry and Psychiatric Epidemiology 2006; 41(9):704-712.

(15) Mattila AK, Kronholm E, Jula A, Salminen JK, Koivisto AM, Mielonen RL et al. Alexithymia and somatization in general population. Psychosomatic Medicine 2008; 70(6):716-722. 
(16) Kroenke K, Spitzer RL. Gender differences in the reporting of physical and somatoform symptoms. Psychosomatic Medicine 1998; 60(2):150-155.

(17) Gureje O, Simon GE, Ustun TB, Goldberg DP. Somatization in cross-cultural perspective: A World Health Organization study in primary care. American Journal of Psychiatry 1997; 154(7):989-995.

(18) Verhaak PFM, Meijer SA, Visser AP, Wolters G. Persistent presentation of medically unexplained symptoms in general practice. Family Practice 2006; 23(4):414-420.

(19) Karvonen JT, Joukamaa M, Herva A, Jokelainen J, Laksy K, Veijola J. Somatization symptoms in young adult Finnish population - Associations with sex, educational level and mental health. Nordic Journal of Psychiatry 2007; 61(3):219-224.

(20) Batty GD, Shipley MJ, Mortensen LH, Boyle SH, Barefoot J, Gronbaek M et al. IQ in late adolescence/early adulthood, risk factors in middle age and later all-cause mortality in men: the Vietnam Experience Study. Journal of Epidemiology and Community Health 2008; 62(6):522-531.

(21) Batty GD, Deary IJ, Gottfredson LS. Premorbid (early life) IQ and later mortality risk: Systematic review. Annals of Epidemiology 2007; 17(4):278-288.

(22) Singh-Manoux A, Ferrie JE, Lynch JW, Marmot M. The role of cognitive ability (intelligence) in explaining the association between socioeconomic position and health: Evidence from the Whitehall II prospective cohort study. American Journal of Epidemiology 2005; 161(9):831-839.

(23) Deary I. Why do intelligent people live longer? Nature 2008; 456(7219):175-176. 
(24) Koenen KC, Moffitt TE, Roberts AL, Martin LT, Kubzansky L, Harrington H et al. Childhood IQ and Adult Mental Disorders: A Test of the Cognitive Reserve Hypothesis. American Journal of Psychiatry 2009; 166(1):50-57.

(25) Henningsen P, Zimmermann T, Sattel H. Medically unexplained physical symptoms, anxiety, and depression: A meta-analytic review. Psychosomatic Medicine 2003; 65(4):528-533.

(26) Iacovides A, Siamouli M. Comorbid mental and somatic disorders: an epidemiological perspective. Current Opinion in Psychiatry 2008; 21(4):417-421.

(27) Pinto-Sietsma SJ, Janssen WMT, Hillege HL, Navis G, De Zeeuw D, de Jong PE. Urinary albumin excretion is associated with renal functional abnormalities in a nondiabetic population. Journal of the American Society of Nephrology 2000; 11(10):1882-1888.

(28) Sanderman R, Eysenck SBG, Arrindell WA. Cross-Cultural Comparisons of Personality - the Netherlands and England. Psychological Reports 1991; 69(3):10911096.

(29) Bosch F, Boomsma-Suerink JL. Manual Generalized Aptitude Test Battery. 1981.

(30) Andrews G, Peters L. The psychometric properties of the composite international diagnostic interview. Social Psychiatry and Psychiatric Epidemiology 1998; 33(2):8088.

(31) Buhrman B, Rainwater L, Schmaus G, Smeeding.T.M. Sensitivity estimates across ten countries using the Luxembourg income study (LIS) data base. Review of Income \& Wealth $1988 ; 2: 115-142$. 
(32) Koeter MWJ. Validity of the Ghq and Scl Anxiety and Depression Scales - A Comparative-Study. Journal of Affective Disorders 1992; 24(4):271-279.

(33) Rosmalen JGM, Neeleman J, Gans ROB, de Jonge P. The association between neuroticism and self-reported common somatic symptoms in a population cohort. Journal of Psychosomatic Research 2007; 62(3):305-311.

(34) Goldberg DP, Gater R, Sartorius N, Ustun TB, Piccinelli M, Gureje O et al. The validity of two versions of the GHQ in the WHO study of mental illness in general health care. Psychological Medicine 1997; 27(1):191-197.

(35) Huisman M. Imputation of missing item responses: Some simple techniques. Quality \& Quantity 2000; 34(4):331-351.

(36) Larsen L, Hartmann P, Nyborg H. The stability of general intelligence from early adulthood to middle-age. Intelligence 2008; 36(1):29-34.

(37) Irwing P, Lynn R. Is there a sex difference in IQ scores? Nature 2006; 442(7098):E1.

(38) Deary IJ, Irwing P, Der G, Bates TC. Brother-sister differences in the g factor in intelligence: Analysis of full, opposite-sex siblings from the NLSY 1979. Intelligence $2007 ; 35(5): 451-456$.

(39) Turner RG, Willerman L. Sex-Differences in Wais Item Performance. Journal of Clinical Psychology 1977; 33(3):795-797.

(40) Escobar JI, Waitzkin H, Silver RC, Gara M, Holman A. Abridged somatization: A study in primary care. Psychosomatic Medicine 1998; 60(4):466-472. 
(41) Kroenke K, Price RK. Symptoms in the Community - Prevalence, Classification, and Psychiatric Comorbidity. Archives of Internal Medicine 1993; 153(21):2474-2480.

(42) Smith GR, Monson RA, Ray DC. Patients with Multiple Unexplained Symptoms Their Characteristics, Functional Health, and Health-Care Utilization. Archives of Internal Medicine 1986; 146(1):69-72.

(43) Babyak MA. What you see may not be what you get: A brief, nontechnical introduction to overfitting in regression-type models. Psychosomatic Medicine 2004; 66(3):411-421.

(44) Gottfredson LS. Dissecting practical intelligence theory: Its claims and evidence. Intelligence $2003 ; 31(4): 343-397$.

(45) Leiknes KA, Finset A, Moum T, Sandanger I. Methodological issues concerning lifetime medically unexplained and medically explained symptoms of the Composite International Diagnostic Interview: a prospective 11-year follow-up study. Journal of Psychosomatic Research 2006; 61(2):169-179.

(46) Duff K, Schoenberg MR, Scott JG, Adams RL. The relationship between executive functioning and verbal and visual learning and memory. Archives of Clinical Neuropsychology 2005; 20(1):111-122.

(47) Batty GD, Deary IJ, Schoon I, Gale CR. Mental ability across childhood in relation to risk factors for premature mortality in adult life: the 1970 British Cohort Study. Journal of Epidemiology and Community Health 2007; 61(11):997-1003. 
(48) Hatch SL, Jones PB, Kuh D, Hardy R, Wadsworth MEJ, Richards M. Childhood cognitive ability and adult mental health in the British 1946 birth cohort. Social Science \& Medicine 2007; 64(11):2285-2296.

(49) Batty GD, Deary IJ, Macintyre S. Childhood IQ and life course socioeconomic position in relation to alcohol induced hangovers in adulthood: the Aberdeen children of the 1950s study. Journal of Epidemiology and Community Health 2006; 60(10):872-874.

(50) Fillmore KM, Golding JM, Graves KL, Kniep S, Leino EV, Romelsjo A et al. Alcohol consumption and mortality. I. Characteristics of drinking groups. Addiction 1998; 93(2):183-203.

(51) Ezzati M, Lopez AD. Estimates of global mortality attributable to smoking in 2000. Lancet 2003; 362(9387):847-852.

(52) Evans J, Repper J. Employment, social inclusion and mental health. Journal of psychiatric and mental health nursing 2000; 7:15-24.

(53) Chrousos GP, Gold PW. The Concepts of Stress and Stress System Disorders Overview of Physical and Behavioral Homeostasis. Jama-Journal of the American Medical Association 1992; 267(9):1244-1252.

(54) Mcewen BS. Central effects of stress hormones in health and disease: Understanding the protective and damaging effects of stress and stress mediators. European Journal of Pharmacology 2008; 583(2-3):174-185. 


\section{Appendix: List of 43 functional somatic symptoms surveyed in the Composite International Diagnostic Interview}

Abdominal pain

Back pain

Joint pain

Pain in extremities

Chest pain

Headache

Pain during urination

Urinary retention

Burning sensation genitals

Pain symptoms additional sites

Vomiting other than during pregnancy

Vomiting throughout pregnancy

Nausea

Diarrhoea

Feeling bloated or full of gas

Intolerance of several foods

Blindness

Blurred vision

Deafness

Impaired balance

Impaired coordination

Loss of touch or pain sensation 
Paralysis

Aphonia

Seizures

Dizziness

Loss of consciousness other than fainting

Amnesia

Double vision

Shortness of breath

Localized weakness

Skin blotches or discoloration

Bad taste in mouth or excessively coated tongue

Frequent urination

Numbness / tingling

Difficulty swallowing or lump in throat

Irregular menses

Excessive menstrual bleeding

Pain during menstruation

Pain during sexual intercourse

Unpleasant sexual intercourse

Other sexual problems including erectile or ejaculatory dysfunction

Sexual indifference 
Table 1: Univariable associations between subject characteristics and intelligence

\section{General intelligence}

\begin{tabular}{llc}
\hline & $\boldsymbol{\beta}\left(\mathbf{R}^{2}\right)$ & $\mathbf{t}$ \\
\hline Age $^{\mathbf{1}}$ & $-0.434 * * *(0.187)$ & -14.797 \\
\hline Female gender $^{2}$ & $-0.183 * * *(0.032)$ & -5.725 \\
\hline Lifestyle factors $^{2}$ & $-0.194 * * *(0.037)$ & -6.093 \\
BMI $^{\mathbf{3}}$ & $-0.095 * *(0.008)$ & -2.937 \\
Smoking $^{\mathbf{4}}$ & $0.237 * * *(0.055)$ & 7.485 \\
Alcohol consumption $^{\mathbf{5}}$ & $0.125 * * *(0.015)$ & 3.871 \\
Exercise frequency $^{\mathbf{6}}$ & & \\
\hline
\end{tabular}

\section{Socio-economic factors}

Educational level $^{8}$

$0.546 * * *(0.298)$

19.345

Work situation?

$0.333 * * *(0.110)$

10.421

Income $^{7}$

$0.244 * * *(0.058)$

7.021

\section{Distress}

GHQ-12 ${ }^{10}$

$-0.019(0.000)$

$-0.591$

All $\beta$ 's are standardized, ${ }^{*} \mathrm{p}<0.05,{ }^{*} \mathrm{p}<0.01, * * * \mathrm{p}<0.001$

${ }^{1}$ Age in years

${ }^{2}$ Gender with " $0 "=$ male, " $1 "=$ female

${ }^{3}$ Body mass index in $\mathrm{kg} / \mathrm{m}^{2}$

${ }^{4}$ Smoking in number of cigarettes/day with " $0 "=0, " 1 "=1-5, " 2 "=6-10, " 3 "=11-15, " 4 "=$ $16-20 ", " 5 "=>20$

${ }^{5}$ Alcohol consumption in number of units with " 0 " = no, almost never, " $1 "=1-4 /$ month, " 2 "= 2-7/week, " $3 "=1-3 /$ day, " $4 "=4$ or more/day

${ }^{6}$ Frequency of exercise with " $0 "=$ no exercise, " $1 "=$ once/week, "2" = twice or more/week 
${ }^{7}$ Educational level with " $1 "=$ none, " $2 "=$ low, " $3 "=$ middle, " $4 "=$ high

${ }^{8}$ Working situation with " 1 " = unwillingly unemployed, "2" = willingly unemployed, "3" = employed

${ }^{9}$ Household income divided by the square root of number of people living of this income

${ }^{10}$ Distress measured by General Health Questionnaire (GHQ)-12 scores 
Table 2: Univariable associations between subject characteristics and the number of 12months FSS and the number of 12-months MES

\begin{tabular}{|c|c|c|c|c|}
\hline & \multicolumn{2}{|c|}{ 12-months FSS } & \multicolumn{2}{|c|}{ 12-months MES } \\
\hline & $\begin{array}{l}\boldsymbol{\beta} \\
\left(\mathbf{R}^{2}\right)\end{array}$ & $\mathbf{t}$ & $\begin{array}{l}\boldsymbol{\beta} \\
\left(\mathbf{R}^{2}\right)\end{array}$ & $\mathbf{t}$ \\
\hline Age $^{1}$ & $\begin{array}{l}0.013 \\
(0.000)\end{array}$ & 0.402 & $\begin{array}{l}0.194 * * * \\
(0.037)\end{array}$ & 6.086 \\
\hline Female gender ${ }^{2}$ & $\begin{array}{l}0.184 * * * \\
(0.033)\end{array}$ & 5.758 & $\begin{array}{l}0.163 * * * \\
(0.026)\end{array}$ & 5.082 \\
\hline \multicolumn{5}{|l|}{ Lifestyle factors } \\
\hline $\mathrm{BMI}^{3}$ & $\begin{array}{l}0.066 * \\
(0.003)\end{array}$ & 2.032 & $\begin{array}{l}0.154 * * * \\
(0.023)\end{array}$ & 4.781 \\
\hline Smoking $^{4}$ & $\begin{array}{l}0.072 * \\
(0.004)\end{array}$ & 2.205 & $\begin{array}{l}0.027 \\
(0.000)\end{array}$ & 0.842 \\
\hline Alcohol consumption ${ }^{5}$ & $\begin{array}{l}-0.098 * * \\
(0.009)\end{array}$ & -3.031 & $\begin{array}{l}-0.105 * * \\
(0.010)\end{array}$ & -3.242 \\
\hline Exercise frequency $^{6}$ & $\begin{array}{l}-0.073 * \\
(0.004)\end{array}$ & -2.256 & $\begin{array}{l}-0.043 \\
(0.001)\end{array}$ & -1.318 \\
\hline Socio-economic factors & & & & \\
\hline Educational level $^{7}$ & $\begin{array}{l}-0.070 * \\
(0.004)\end{array}$ & -2.089 & $\begin{array}{l}-0.150 * * * \\
(0.021)\end{array}$ & -4.493 \\
\hline Work situation $^{8}$ & $\begin{array}{l}-0.170 * * * \\
(0.028)\end{array}$ & -5.097 & $\begin{array}{l}-0.180 * * * \\
(0.031)\end{array}$ & -5.379 \\
\hline Income $^{9}$ & $\begin{array}{l}-0.131 * * * \\
(0.016)\end{array}$ & -3.696 & $\begin{array}{l}-0.108 * * \\
(0.010)\end{array}$ & -3.039 \\
\hline
\end{tabular}




\section{Distress}

\begin{tabular}{|c|c|c|c|}
\hline GHQ-12 & $0.308 * * *$ & 9.941 & $0.163 * * *$ \\
\hline & $(0.094)$ & & $(0.025)$ \\
\hline
\end{tabular}

Abbreviations: FSS, functional somatic symptoms; MES, medically explained symptoms.

All $\beta$ 's are standardized, $* \mathrm{p}<0.05, * * \mathrm{p}<0.01, * * * \mathrm{p}<0.001$

${ }^{1}$ Age in years

${ }^{2}$ Gender with " $0 "$ = male, " 1 " = female

${ }^{3}$ Body mass index in $\mathrm{kg} / \mathrm{m}^{2}$

${ }^{4}$ Smoking in number of cigarettes/day with " $0 "=0, " 1 "=1-5, " 2 "=6-10, " 3 "=11-15, " 4 "=$ $16-20 ", " 5 "=>20$

${ }^{5}$ Alcohol consumption in number of units with " 0 " = no, almost never, " 1 " = 1-4/month, " 2 " = 2-7/week, "3" = 1-3/day, "4" = 4 or more/day

${ }^{6}$ Frequency of exercise with" $0 "$ = no exercise, " $1 "=$ once/week, " $2 "=$ twice or more/week

${ }^{7}$ Educational level with "1" = none, "2" = low, "3" = middle, "4" = high

${ }^{8}$ Working situation with " $1 "=$ unwillingly unemployed, "2" = willingly unemployed, "3" = employed

${ }^{9}$ Household income divided by the square root of people living of this income

${ }^{10}$ Distress measured by General Health Questionnaire (GHQ)-12 scores 
Table 3: Multivariable associations between intelligence and 12-months FSS and 12months MES (all adjusted for age ${ }^{1}$ and gender $^{2}$ )

\begin{tabular}{|c|c|c|c|c|}
\hline & \multicolumn{2}{|c|}{ 12-months FSS } & \multicolumn{2}{|c|}{ 12-months MES } \\
\hline & $\begin{array}{l}\boldsymbol{\beta} \\
\left(\mathbf{R}^{2}\right)\end{array}$ & $\mathbf{t}$ & $\begin{array}{l}\boldsymbol{\beta} \\
\left(\mathbf{R}^{2}\right)\end{array}$ & $\mathbf{t}$ \\
\hline General intelligence & $\begin{array}{l}-0.084 * \\
(0.037)\end{array}$ & -2.299 & $\begin{array}{l}-0.095 * * \\
(0.074)\end{array}$ & -2.652 \\
\hline Dimensional space subtest & $\begin{array}{l}-0.035 \\
(0.031)\end{array}$ & -0.968 & $\begin{array}{l}-0.018 \\
(0.067)\end{array}$ & -0.496 \\
\hline Vocabulary subtest & $\begin{array}{l}-0.071 * \\
(0.036)\end{array}$ & -2.059 & $\begin{array}{l}-0.086 * \\
(0.073)\end{array}$ & -2.521 \\
\hline Arithmetic reasoning subtest & $\begin{array}{l}-0.094 * * \\
(0.038)\end{array}$ & -2.732 & $\begin{array}{l}-0.116 * * \\
(0.078)\end{array}$ & -3.438 \\
\hline $\begin{array}{l}\text { General intelligence + lifestyle } \\
\text { factors + socio-economic factors }\end{array}$ & & & & \\
\hline Intelligence & -0.010 & -0.205 & -0.043 & -0.889 \\
\hline BMI $^{3}$ & 0.064 & 1.620 & 0.072 & 1.831 \\
\hline Smoking $^{4}$ & 0.057 & 1.446 & 0.065 & 1.651 \\
\hline Alcohol consumption ${ }^{5}$ & -0.018 & -0.454 & -0.009 & -0.226 \\
\hline Exercise $^{6}$ & -0.047 & -1.213 & 0.013 & 0.327 \\
\hline Educational level $^{7}$ & -0.039 & -0.822 & -0.043 & -0.922 \\
\hline Work $^{8}$ & $-0.142 * *$ & -3.363 & -0.045 & -1.088 \\
\hline Income $^{9}$ & $\begin{array}{l}-0.030 \\
(0.067)\end{array}$ & -0.696 & $\begin{array}{l}-0.038 \\
(0.085)\end{array}$ & -0.886 \\
\hline
\end{tabular}


Abbreviations: FSS, functional somatic symptoms; MES, medically explained symptoms

All $\beta$ 's are standardized, *p $<0.05, * * p<0.01, * * * p<0.001$

${ }^{1}$ Age in years

${ }^{2}$ Gender with " $0 "=$ male, " $1 "=$ female

${ }^{3}$ Body mass index in $\mathrm{kg} / \mathrm{m}^{2}$

${ }^{4}$ Smoking in number of cigarettes/day with " $0 "=0, " 1 "=1-5, " 2 "=6-10, " 3 "=11-15, " 4 "=$ $16-20, " 5 "=>20$

${ }^{5}$ Alcohol consumption in number of units with " 0 " = no, almost never, " 1 " = 1-4/month, " 2 " = 2-7/week, "3" = 1-3/day, "4" = 4 or more/day

${ }^{6}$ Frequency of exercise with " $0 "=$ no exercise, " $1 "=$ once/week, "2" = twice or more/week

${ }^{7}$ Educational level with "1" = none, "2" = low, "3" = middle, " $4 "=$ high

${ }^{8}$ Working situation with " $1 "=$ unwillingly unemployed, "2" = willingly unemployed, "3" = employed

${ }^{9}$ Household income divided by the square root of number of people living of this income 
License statement

The Corresponding Author has the right to grant on behalf of all authors and does grant on behalf of all authors, an exclusive licence (or non exclusive for government employees) on a worldwide basis to the BMJ Publishing Group Ltd and its Licensees to permit this article (if accepted) to be published in JECH editions and any other BMJPGL products to exploit all subsidiary rights, as set out in our licence (http://jech.bmj.com/ifora/licence.pdf) 